\title{
Dens Invaginatus: A Report of Two Cases
}

\author{
Archna Agnihotri1,® Rosy Arora ${ }^{1} \quad$ Lalit Bida $^{2} \quad$ Urvashi Sharma ${ }^{1}$ \\ ${ }^{1}$ Department of Pedodontics, Dr HSJ Institute of Dental Sciences, \\ Address for correspondence Archna Agnihotri, MDS, \\ Panjab University, Chandigarh, India \\ 2 Department of Prosthodontics, Dr HSJ Institute of Dental Sciences, \\ Department of Pedodontics, Dr HSJ Institute of Dental Sciences, \\ Panjab University, Chandigarh, India \\ Panjab University, Chandigarh, India \\ (e-mail: archna.agnihotri@gmail.com).
}

Dent J Adv Stud:2021;9:51-54

\begin{abstract}
Keywords

- dens invaginatus

- cone beam

tomography

- dens in dente

Dens invaginatus (DI) is an anomaly of developmental origin arising due to disturbances during the morphodifferentiation stage, resulting from infolding of enamel organ toward the dental papilla. Different presentations of the invagination, altered canal morphology, and presence of constrictions and dilatations sometimes make its management really challenging. With the advent of modern diagnostic and treatment aids, their easy availability and routine use, it is now possible to have detailed view of the invagination, thus making the management easy and the outcome predictable. This article presents two different presentations of DI and their management.
\end{abstract}

\section{Introduction}

Dens invaginatus (DI), also termed as dens in dente and dilated composite odontoma, is one of the most common dental malformations. It results from infolding (full or partial) of enamel organ into the dental papilla before the start of the calcification stage. Maxillary incisors are the most commonly affected teeth, followed by premolars, canines and molars. ${ }^{1-5}$ Presence of atypical crown morphology or a deepened pit in the cingulum area may lead to the suspicion of DI. In the absence of any signs or symptoms of malformation, it might sometimes go unnoticed unless the patient seeks a routine professional consultation. Bilateral involvement of teeth has also been reported, so if a tooth has been found to be affected with DI, the contralateral tooth should also be examined. ${ }^{6}$

Dens in dente usually appears as an invagination at the site of lingual pit in cingulum area, which is separated by a thin layer of dentine from the pulp, making it prone to caries, pulpal necrosis, periapical or periodontal abscess. Radiographically, it might appear as an invagination with radiopacity equivalent to that of the enamel within the crown or might extend to various levels into the root. ${ }^{5}$ Oehlers classified dens in dente based on the extent of the invagination from the crown portion into the root radiographically as under. ${ }^{7}$

published online March 3, 2021
DOI https://doi.org/

$10.1055 / \mathrm{s}-0041-1725219$

ISSN 2321-1482.
Type I: It ends as a blind sac into the crown, appearing as an enamel-lined invagination of minor form contained within the confines of the crown and not extending beyond the cementoenamel junction (CEJ).

Type II: Enamel-lined invagination extending beyond the cementoenamel junction as a blind sac; it may or may not communicate with the pulp but does not extend to the periodontal membrane or apical tissues.

Type IIIa: The invagination extends through the root and communicates with the periodontal ligament (PDL) through a pseudoforamen. There is usually no communication with the pulp, which lies compressed within the root.

Type IIIb: The invagination extends through the root and communicates with the PDL at the apical foramen. There is usually no communication with the pulp.

Ridell et al reported the prevalence for each type of invagination based on Oehlers classification. Type I was found to be most prevalent (79\%) followed by type II (15\%) and type III (5\%). Majority of lateral incisors (85\%) with invagination were found to be having type III DI. ${ }^{8}$

Due to abnormal configuration, a tooth with DI presents with certain technical difficulties during its clinical management, and prognosis also sometimes remains guarded. Various treatment modalities have been advocated, based on the type and extent of invagination include prophylactic

(C)2021. Bhojia Dental College and Hospital affiliated to Himachal Pradesh University.

This is an open access article published by Thieme under the terms of the Creative Commons Attribution-NonDerivative-NonCommercial-License, permitting copying and reproduction so long as the original work is given appropriate credit. Contents may not be used for commercial purposes, or adapted, remixed, transformed or built upon. (https://creativecommons.org/licenses/by-nc-nd/4.0/).

Thieme Medical and Scientific Publishers Pvt. Ltd. A-12, 2nd Floor, Sector 2, Noida-201301 UP, India 
restoration, root canal treatment, endodontic surgery, intentional replantation and extraction. ${ }^{9-12}$ This article presents report of two cases of DI with different configurations and their management.

\section{Case Report}

A 17-year-old girl reported with the chief complaint of difficulty in chewing food and swelling on the right side of the hard palate. The patient reported that swelling decreased in size when she was on a course of antibiotics advised by a private practitioner, but never regressed fully. Now since past 2 months, it had gradually increased to the present size. Medical history was found to be noncontributory. Intraoral examination revealed a palatal swelling in relation to right maxillary lateral incisor ( - Fig. 1A). The swelling was firm, immobile, and tender on palpation with normal color of overlying mucosa. The palatal surface of the lateral incisor presented with very fine deep pit in the cingulum area. Maxillary anterior teeth were subjected to electric pulp testing; right maxillary central and lateral incisor failed to respond to the pulp testing, whereas all other teeth responded within normal limits.

Periapical radiograph showed invagination in maxillary lateral incisor with radiopacity equivalent to that of enamel, extending from the cingulum slightly beyond $\mathrm{CEJ}$ into the root canal along with a periapical radiolucency, extending up to the distal aspect of central incisor.

A clinical diagnosis of DI (Oehlers type 2) in maxillary lateral incisor with pulpal necrosis and chronic periapical abscess was made (-Fig. 1B). Access was gained in both the teeth. In maxillary lateral incisor, the enamel invagination could be
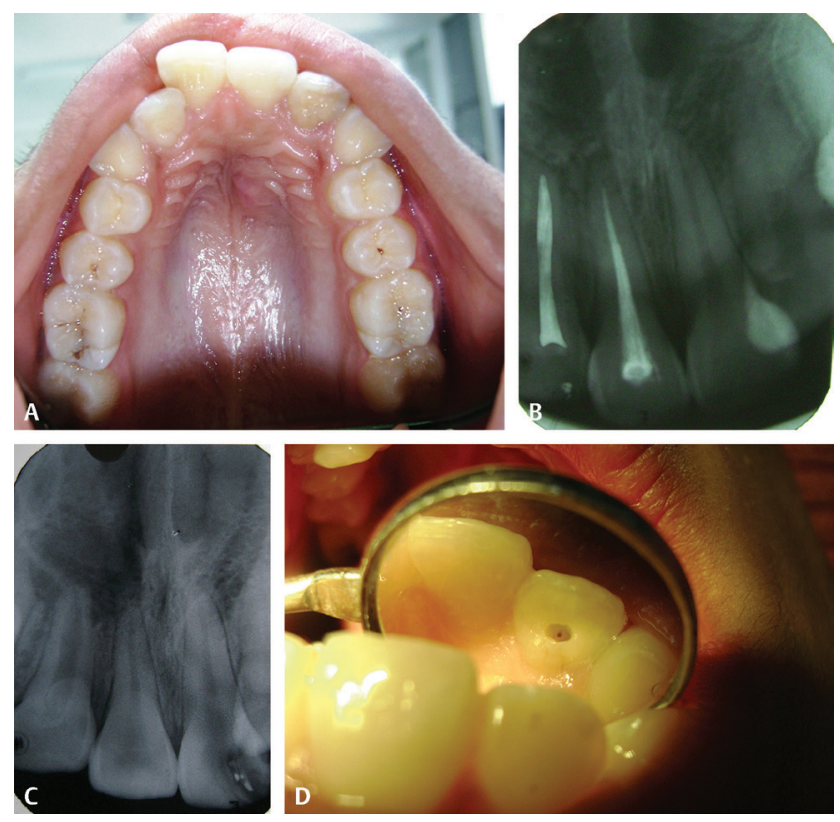

Fig. 1 (A) Showing palatal swelling in relation to right maxillary lateral incisor. (B) Periapical radiograph showing dens invaginatus (DI) in right maxillary lateral incisor and periapical radiolucency extending up to distal aspect of central incisor. (C) Showing enamel invagination deep into the root communicating with root canal type II DI. (D) Showing obturated root canals and complete healing of the periapical area. seen extending into the root canal ( - Fig. 1C). The invagination was cleared with the help of slow-speed Gates-Glidden drill and manual $\mathrm{H}$ and $\mathrm{K}$ files, and irrigation was done with $2.5 \%$ sodium hypochlorite to remove the debris thoroughly.

After establishing the working length, calcium hydroxide was placed in the root canals of both the teeth and restored with glass-ionomer cement (GIC). The patient was recalled after 3 months to check for the dissolution and refilling. The canals were irrigated and refilled with calcium hydroxide, and the patient was recalled again after 3 months. Serial radiographs showed healing in the periapical area with complete resolution of palatal swelling. The canals were then obturated with gutta percha and coronal restoration. The patient was kept on periodic recall and the healing was uneventful. Radiograph examination after 1 year showed complete osseous healing of periapical area ( - Fig. 1D), and the patient remained asymptomatic.

\section{Case II}

A 13-year-old boy presented with the chief complaint of trauma and fractured restoration in upper front tooth. History revealed trauma to anterior teeth 2 years back, which led to the fracture of upper front tooth and was restored by a private practitioner. Medical history was found to be noncontributory. Intraoral and radiographic examinations revealed fractured right maxillary central incisor with a radiopaque fractured residual filling ( - Fig. 2 A). An invagination was seen
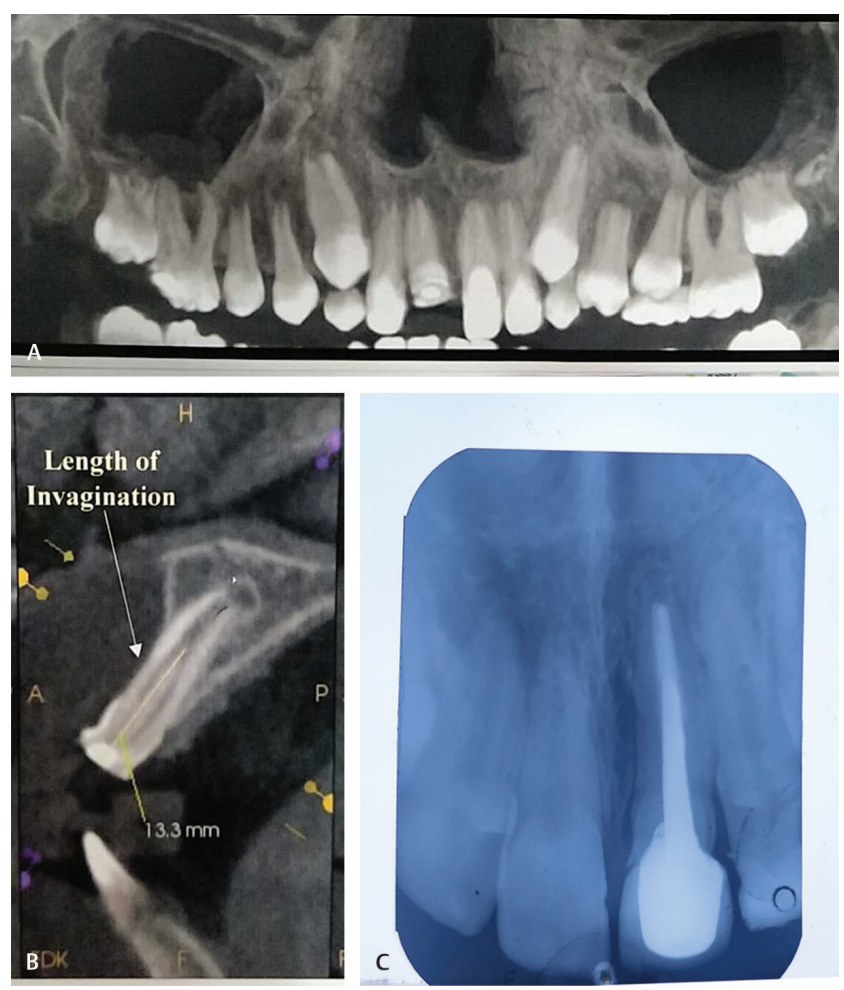

Fig. 2 (A) Showing panoramic view of the dentition. (B) Showing length of the invagination cone-beam computed tomography (CBCT). (C) Showing postoperative intraoral periapical (IOPA) view at 1-year follow-up. 
within the main canal centrally, extending from the crown to the apical third of the root, associated with the widening of PDL. No response was generated from the tooth during electric pulp testing, and the diagnosis of Oehlers type II DI with pulpal necrosis and chronic apical periodontitis was made. Cone-beam computed tomography (CBCT) was requested to completely assess the invagination and avoid any complications during the treatment. $\mathrm{CBCT}$ revealed an invagination of $13.3 \mathrm{~mm}$, extending from the crown into the root surrounded by radiolucent lines on both sides, communicating with the pulpal tissue of main canal through an apical opening (-Fig. 2B). After the local anesthesia (LA) administration and placement of rubber dam, access was gained with high-speed diamond burs. The invagination was removed with the help of manual $\mathrm{H}$ and $\mathrm{K}$ files along with slow-speed Gates-Glidden drills. The instruments were brushed along the wall to remove the invagination and achieve a smooth outline of the wall till the apex.

Debridement and irrigation was done with $2.5 \%$ sodium hypochlorite. The canal was then filled with calcium hydroxide and closed with GIC restoration, and patient was recalled after 2 weeks. The canal was then obturated, followed by the placement of post and core and crown. The patient was placed on regular recall and with successful outcome at 1-year follow-up (-Fig. 2C).

\section{Discussion}

DI is a condition of rare occurrence in primary dentition, but has been found frequently in permanent dentition, having a prevalence rate of 0.04 to $10 \%$ with female predilection of 3:1 and a high degree of inheritance. ${ }^{1-4}$ An early diagnosis of such anomalies can prevent pulpal degeneration and necrosis in certain cases. The 2-dimensional (2D) radiographs such as periapical and panoramic examination are being commonly used in endodontic diagnosis. Teeth affected with DI, in which the invagination extends further into the root canal, generally present with altered morphology with formation of wave-like constrictions and dilatations. With the advent of CBCT and its easy availability, it has now become a routine diagnostic aid in dentistry for 3-dimensional (3D) evaluation of such malformations, providing better diagnosis and hence treatment with a predictable and successful outcome. ${ }^{13}$

It is important for the clinicians to keep themselves abreast with the methods of treating various anatomical variations of teeth such as DI. Based upon the type and complexity of invagination, treatment may vary from no intervention with regular follow-up, prophylactic restoration, nonsurgical endodontic treatment, pulp revascularization to surgical approach, or extraction.

In the first case, the invagination was found to be well within the confines of the root and ended as a blind sac. Combined use rotary and hand instruments along with $\mathrm{NaOCl}$ helped in complete removal of invagination. As calcium hydroxide has been reported to successfully eliminate bacteria and stimulate hard-tissue formation, same was achieved in this case before obturating the root canal with gutta percha. ${ }^{13,14}$ In the second case, the invagination extended deep into the canal, which required detailed viewing of the configuration with the help of CBCT. Due to available in-depth view of the invagination provided by $\mathrm{CBCT}$, it became easier to completely clear the invagination with help of slow rotatory instruments and hand files. Since the invagination was surrounded by pulpal tissue, it was possible to remove it in toto and obtain a smooth canal wall for receiving final root canal filling, as has also been reported earlier. ${ }^{15-18}$ Thorough debridement with the help of sodium hypochlorite and disinfecting the canal with calcium hydroxide helped to achieve the successful outcome at long-term follow-up.

\section{Conclusion}

DI is a malformation of clinical significance, requiring early and accurate diagnosis to prevent complications. With the advent of new diagnostic aids and their routine use, it is now possible to precisely understand the morphological deviations and plan the treatment accordingly.

\section{Conflict of Interest}

None declared.

\section{References}

1 Mupparapu M, Singer SR. A rare presentation of dens invaginatus in a mandibular lateral incisor occurring concurrently with bilateral maxillary dens invaginatus: case report and review of literature. Aust Dent J 2004;49(2):90-93

2 Galindo-Moreno PA, Parra-Vázquez MJ, Sánchez-Fernández E, Avila-Ortiz GA. Maxillary cyst associated with an invaginated tooth: a case report and literature review. Quintessence Int 2003;34(7):509-514

3 O'Sullivan EA. Multiple dental anomalies in a young patient: a case report. Int J Paediatr Dent 2000;10(1):63-66

4 Hülsmann M. Dens invaginatus: aetiology, classification, prevalence, diagnosis, and treatment considerations. Int Endod J 1997;30(2):79-90

5 White SC, Pharoah MJ, Oral Radiology Principles and Interpretation. 4th ed. St Louis; Mosby: 2000 314-315

6 Canger EM, Kayipmaz S, Celenk P. Bilateral dens invaginatus in the mandibular premolar region. Indian J Dent Res 2009;20(2):238-240

7 Oehlers FAC. Dens invaginatus (dilated composite odontome). I. Variations of the invagination process and associated anterior crown forms. Oral Surg Oral Med Oral Pathol 1957;10(11):1204-1218

8 Ridell K, Mejàre I, Matsson L. Dens invaginatus: a retrospective study of prophylactic invagination treatment. Int J Paediatr Dent 2001;11(2):92-97

9 de Sousa SM, Bramante CM. Dens invaginatus: treatment choices. Endod Dent Traumatol 1998;14(4):152-158

10 Hosey MT, Bedi R. Multiple dens invaginatus in two brothers. Endod Dent Traumatol 1996;12(1):44-47

11 Bolanos OR, Martell B, Morse DR. A unique approach to the treatment of a tooth with dens invaginatus. J Endod 1988;14(6):315-317

12 Lindner C, Messer HH, Tyas MJ. A complex treatment of dens invaginatus. Endod Dent Traumatol 1995;11(3):153-155

13 Zhu J, Wang X, Fang Y. Von den Hoff JW, Meng L. An update on the diagnosis and treatment of dens invaginatus. Aust Dent J 2017;62(3):261-275 
14 Heithersay GS. Calcium hydroxide in the treatment of pulpless teeth with associated pathology. J Br Endod Soc 1975;8(2):74-93

15 Gharechahi M, Ghoddusi J. A nonsurgical endodontic treatment in open-apex and immature teeth affected by dens invaginatus: using a collagen membrane as an apical barrier. J Am Dent Assoc 2012;143(2):144-148

16 Ma R, Kaiwar A, N M, et al. Nonsurgical endodontic treatment of type II dens invaginatus. J Conserv Dent 2009;12(2):73-76
17 Tsurumachi T. Endodontic treatment of an invaginated maxillary lateral incisor with a periradicular lesion and a healthy pulp. Int Endod J 2004;37(10):717-723

18 Pai SF, Yang SF, Lin LM. Nonsurgical endodontic treatment of dens invaginatus with large periradicular lesion: a case report. J Endod 2004;30(8):597-600 